\title{
Pre-hospital emergency care system: Utilization of ambulance services in Nairobi county
}

\author{
Felistus Ndanu Musyoka, ${ }^{1}$ Abdushakur Ndolo Kioko ${ }^{2}$ \\ ${ }^{1}$ Nairobi Metropolitan Services, Nairobi; ${ }^{2}$ Exactitude Research Consultants, Nairobi, Kenya
}

\begin{abstract}
Emergency Medical Service (EMS) is the system that organizes all aspects of medical care provided to patients in the pre-hospital environment and emergency department within hospitals. It comprises agencies and organizations (both private and public), communication and transportation networks, hospitals, highly trained professionals and a public aware on how to respond in emergencies. Kenya needs robust EMS due to the high prevalence of acute medical events such as COVID-19, natural and man-made disasters. The objective of this study was to assess utilization of ambulance services in Nairobi County. The study design was
\end{abstract}

Correspondence: Felistus Ndanu Musyoka, Nairobi Metropolitan Services, P.O. Box 29944-00100 GPO, Nairobi, Kenya.

Tel.: +254723961187

E-mail: felistusmusyoka506@gmail.com

Key words: Awareness of emergency services; ambulances; pre-hospital emergency care; emergency medical service; Kenya.

Acknowledgments: The authors would like to thank Nairobi Metropolitan Services, the Ministry of Health, and the Department of Emergency and Disasters Risk Reduction for the ethics approval.

Conflict of interest: The authors declare no conflict of interest.

Availability of data and materials: All data generated or analyzed during this study are included in this published article.

Ethics approval and consent to participate: The Ethics Committee of Nairobi Metropolitan Services approved this study (NMS/D/213/2020). The study is conformed with the Helsinki Declaration of 1964, as revised in 2013, concerning human and animal rights. All patients participating in this study signed a written informed consent form for participating in this study.

Informed consent: Written informed consent was obtained from a legally authorized representative(s) for anonymized patient information to be published in this article.

Received for publication: 13 October 2021.

Revision received: 21 November 2021.

Accepted for publication: 22 November 2021.

This work is licensed under a Creative Commons Attribution 4.0 License (by-nc 4.0).

${ }^{\circ}$ Copyright: the Author(s), 2021

Licensee PAGEPress, Italy

Emergency Care Journal 2021; 17:10217

doi:10.4081/ecj.2021.10217 descriptive cross-sectional, using quantitative and qualitative research methods. Data was collected using interviewer-administered semi-structured questionnaires and key in-depth interviews from 14 ambulance services, 19 Emergency Care Centers (ECC), and community. Thirty-nine key informants were sampled using purposive sampling technique and 101 community members sampled using simple random sampling technique from 10 sub-counties. Data tools were pretested at Mukuru Kwa Njenga, a populous slum in Nairobi County. Approval to carry out the study was granted by the Ministry of Health, Kenya. Qualitative data was analyzed using NVIVO12 and quantitative data analyzed using descriptive statistics by use of SPSS vs 25 software. Findings are represented as frequencies and percentages. There were 14 ambulance service providers in the Nairobi Metropolitan Services area with a total of 42 ambulances. Forty-one ambulances were facility-based ambulances. All ambulance services had emergency numbers, and only 3 had short-toll free ambulance access numbers. There were 9 different ambulance dispatch centers in the county. Five ambulance services did not have a dispatch Centre. Public members were the first to assist in in $79 \%$ emergencies. There was low public awareness on available pre-hospital emergency care services and tollfree lines for emergency services. Ambulances utilization was also low.

\section{Introduction}

Emergency Medical Service (EMS) is the system that organizes all the aspects of emergency medical care provided to patients in the pre-hospital or out-of-hospital environment, and to the emergency unit in a hospital. Emergency care system comprises of agencies and organizations (both private and public), communication and transportation networks, hospitals, specialty care centers, rehabilitation facilities, highly trained professionals and an informed public that knows what to do in a medical emergency. Apart from being a common resource for a variety of medical conditions, EMS is also the foundation for effective disaster response and management of mass casualty incidents. ${ }^{1}$ The organization and provision of EMS vary from country to country and sometimes between regions within a country. While many models of pre-hospital care are described in literature, in Low And Middle-Income Countries (LMICs) EMS systems are generally fragmented and largely limited to transportation without protocols for field triage, standards of care, or communication to receiving facilities. ${ }^{2}$ The lay public is often left to decide independently whether and where to transfer the acutely ill or injured patients. A recent landscape analysis demonstrated that less than one in three African countries has a pre-hospital EMS in place with limited capacity to respond, evaluate, treat, and safely transport patients. ${ }^{3}$

The Kenya Emergency Medical Care (EMC) Policy 20202030 is the first-ever policy in Kenya that seeks to establish a working EMC System as a key component of the healthcare system in the country. The newly developed policy aims to ensure 
access to the highest standards of emergency medical care in Kenya as envisioned in The Constitution of Kenya (2010) and the Health Act (2017), which guarantees every Kenyan the right to emergency medical treatment. The policy also speaks to the World Health Assembly resolution WHA 72.16 of $21^{\text {st }}$ May 2019, which urged member states to create policies for sustainable funding, effective governance and universal access to safe, high-quality, and needs-based emergency care for all as part of a universal health coverage.

The study by Broccoli et al. opined that $45 \%$ of deaths and $36 \%$ of disabilities in low-income and middle-income countries could be addressed by timely emergency care. ${ }^{4}$ A scoping review of published studies and grey literature noted that Africa accounts for about $90 \%$ of the global trauma burden. Post-trauma mortality ranged from $13 \%$ in Ghana to $40 \%$ in Nigeria. Reported preventable mortality is as high as $70 \%$ in South Africa, $60 \%$ in Ghana and $40 \%$ in Nigeria. ${ }^{5}$ A different study by Macharia et al. showed that out of 310 road traffic injury casualties interviewed, $76.5 \%$ were transported to hospitals by unknown persons who were predominantly other road users or general public, that had no or little knowledge on first aid. ${ }^{6}$ A study conducted by Nicholson et al. noted that majority of EMS deaths were due to delayed response, lack of knowledge on identifying critical patients and how to handle them. ${ }^{7}$

Kenya has an undisputed and strong need for a robust EMS. The high prevalence of acute medical events, natural and manmade disasters such as road traffic crashes, building collapse, fire, and mass casualty incidents have created an increasingly large demand for a reliable, integrated, and safe EMS system in Kenya. ${ }^{8}$ Further, increasing vehicular traffic combined with rapid urbanization, and the introduction of motorcycles to Kenya's roads have contributed to more than 8,000 deaths annually from road traffic injures. Kenya has neither a coordinated, integrated pre-hospital care system, nor a triage system to route injured patients to appropriate care facilities in a timely nature. ${ }^{9}$ A study conducted by Saidi in 2003 in Nairobi showed that a slow response to injury,with a mean pre-hospital time of 2.56 hours and only $17.5 \%$ patients reached their areas of definitive care within 60 minutes, and haphazard. ${ }^{10}$

The majority of Kenya's citizens receive health care through a publicly funded system governed by the country's Ministry of Health. ${ }^{9}$ Despite the demand, EMS in Kenya remains underdeveloped, underequipped and unsophisticated due to the lack of skilled professionals, resources (i.e., ambulances), and an organized national emergency or trauma care system. ${ }^{11}$ In order to revamp and have an effective and efficient emergency care service delivery with timely access to emergency care in Nairobi County and Kenya at large, there is a need to establish utilization patterns of ambulance services. Anecdotal evidence suggests that the access to pre-hospital care interventions, the level of provider skills and referral pathways are important determinants of mortality out- comes. ${ }^{5}$ This will improve the access to quality life-saving emergency care, reducing the high morbidity and mortality currently experienced within Nairobi County and other counties across Kenya.

\section{Materials and Methods}

This descriptive cross-sectional study utilized both quantitative and qualitative research methods. The study was carried out in Nairobi County, made by 17 administrative sub-counties, which belong to the larger Nairobi Metropolitan Services (NMS) territory. Data was collected using interviewer-administered semi-structured questionnaires and key in-depth interviews from 14 ambulance services, 19 emergency care centers (health care facilities with high volume of emergency cases, that handle both medical and surgical emergencies 24 hours a day), and community. Thirtynine key informants were collected using purposive sampling technique, and 101 community members sampled using simple random sampling technique from 10 health-related sub-counties, that form the seventeen administrative sub-counties. Data tools were pretested at Mukuru Kwa Njenga, a populous slum in Nairobi County. Approval to carry out the study was granted by the Ministry of Health; authorized by the NMS Health Directorate and facilitated by the Division of Health emergencies and referral services. Verbal consent was given by respondents. Qualitative data was thematically analyzed using NVIVO 12 and quantitative data using descriptive statistics with SPSS vs 25 software.

\section{Results}

\section{Ambulances}

All the emergency care centers assessed had an ambulance, except two facilities. There were 14 ambulance service providers, and a total of 83 ambulances in NMS area. Forty-two ambulances were in dispatch centers, while 41 ambulances were in health facilities. Forty-two ambulances had Basic Life Support (BLS) and 41 ambulances had Advanced Life Support (ALS). As reported in Table 1, out of 83 ambulances, 41 BLS and 41 ALS had been accredited by Kenya Bureau of Standards (KEBS); and 24 BLS and 23 ALS ambulances had been ISO certified. As reported in Table 2, considering the 41 facility-based ambulances, 9 belonged to NMS, 7 to the Ministry of Health, 20 to private entrepreneurs, and 5 to faith-based organizations. ALS had nurses and emergency medical technicians in an ambulance equipped with airway equipment, cardiac life support, cardiac monitor and glucose testing device, as shown in Figure 1. BLS had two emergency medical technicians and not fully equipped.

Table 1. Total number of ambulances assessed in the study.

\begin{tabular}{|c|c|c|c|c|c|c|c|}
\hline \multirow[b]{2}{*}{$\begin{array}{l}\text { Ambulance service } \\
\text { providers }\end{array}$} & \multicolumn{6}{|c|}{$\begin{array}{l}\text { Number of Ambulances } \\
\text { Basic Life Support (BLS) }\end{array}$} & \multirow[t]{2}{*}{ Tota } \\
\hline & $\begin{array}{l}\text { Total No. of } \\
\text { ambulances }\end{array}$ & $\begin{array}{l}\text { Meet KEBS } \\
\text { criteria }\end{array}$ & $\begin{array}{l}\text { ISO } \\
\text { certified }\end{array}$ & $\begin{array}{l}\text { Total no. of } \\
\text { ambulances }\end{array}$ & $\begin{array}{l}\text { Meet KEBS } \\
\text { criteria }\end{array}$ & $\begin{array}{l}\text { ISO } \\
\text { certified }\end{array}$ & \\
\hline Dispatch center & 21 & 21 & 16 & 21 & 21 & 13 & 42 \\
\hline EMC/health facilities & 21 & 20 & 8 & 20 & 20 & 10 & 41 \\
\hline Total & 42 & 41 & 24 & 41 & 41 & 23 & 83 \\
\hline
\end{tabular}




\section{Communication}

All the ambulance service providers had separate emergency numbers operational 24-hours a day. Only three ambulance services had a short-code toll free ambulance access number, while service provider calling rates applied for the rest. None of the health facilities had a single short code toll-free emergency access number.

The emergency number was operated through an IT system in half $(50 \%)$ of the ambulance services, while $43 \%$ used a manual telephone system, and $7 \%$ had both. The emergency number had been publicized by public promotion only in $38.5 \%$ of cases. Car stickers, billboards, branding of ambulances, advertising through media and websites was implemented at $16.7 \%$. Half of the ambulance services used physical forms to record information when contacted, while only $42.9 \%$ had an IT system in place.

The majority (64\%) of the ambulance services had a dispatch center managed by independent agencies, while the rest had the ambulances staff receiving emergency calls directly. Only 9 dispatch centers had the minimum requirements in line with internationally accepted standards of vital data capturing and global positioning system. At the time of the study, NMS had an emergency operations center operational 24 hours for coordination of emergencies. Trained ambulance dispatchers were available in only 6 of the ambulance service providers, while the rest used trained medical personnel (i.e., nurses) or EMTs. The shifts for the ambulance dispatchers ran for a median of 12 hours, ranging from 8 to 48 hours. People responsible to answer emergency calls at the health facilities were nurse-in-charge (44\%) and hospital receptionists $(35 \%)$. Other health facilities utilized paramedics and trained EMTs (17\%), and doctors (4\%) within the hospitals to answer the emergency calls.

\section{Community and pre-hospital emergency care}

Most $(56 \%)$ of the respondents interviewed were aware of what a medical emergency is, having either experienced or witnessed someone in an emergency. Many (90\%) of the respondents were aware of the role of ambulances in the emergency response. The majority (70\%) of the respondents were not aware of the emergency contact numbers for the ambulances. The most common emergency was accidents (55\%), followed by breathing problems $(23 \%)$, birth complications (9\%), non-communicable diseases such as severe malaria $(9 \%)$ and food poisoning $(4 \%)$. All the emergencies got someone to assist. As shown in Figure 2, community members were the first to assist in $79 \%$ of the emergencies. Community members included family members $(33 \%)$, good Samaritans $(16 \%)$, friends $(15 \%)$, relatives $(9 \%)$, and neighbors $(5 \%)$. Other responders were police $(16 \%)$ and emergency responders $(5 \%)$. In the event of an emergency, the majority $(96 \%)$ of the emergencies needed to be transport to the hospital. Ambulances were used by $37 \%$ of the respondents, as shown in Figure 3.

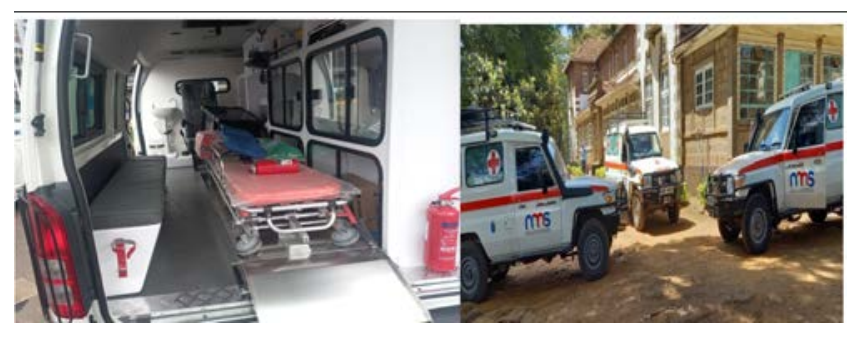

Figure 1. Nairobi Metropolitan Services - Advanced Life Support Ambulance.

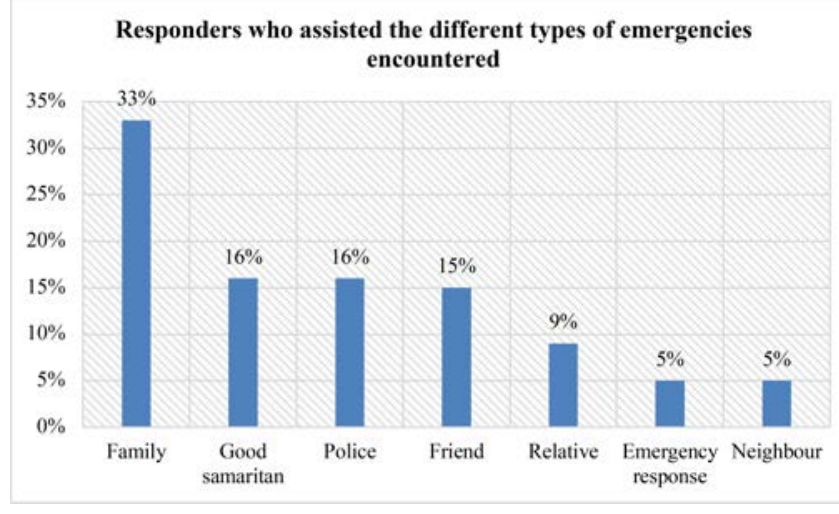

Figure 2. Responders who assisted the different types of emergencies encountered.

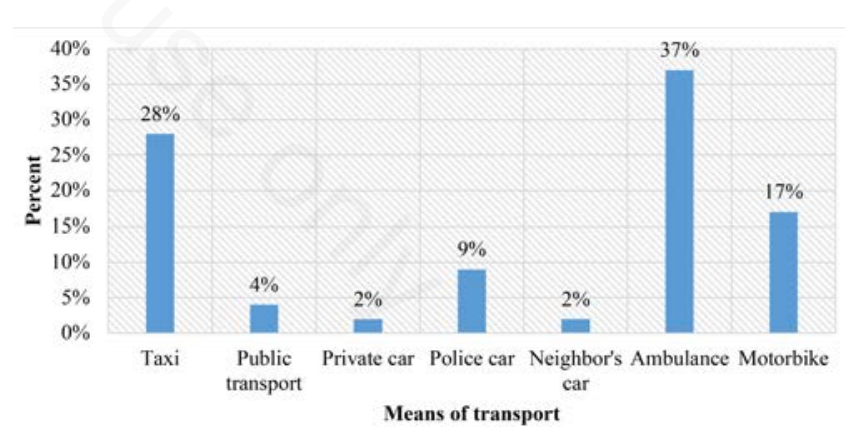

Figure 3. Means of transport.

Table 2. Distribution of hospital based ambulances.

\begin{tabular}{lccc}
\hline Hospital ownership & \multicolumn{2}{c}{ Number of ambulances } & Total \\
& Basic Life Support (BLS) & Advanced life Support (ALS) & 9 \\
County & 6 & 3 & 7 \\
Ministry of Health & 5 & 2 & 20 \\
\hline Private & 7 & 13 & 5 \\
Faith-Based Organization (FBO) & 3 & 2 & 41 \\
\hline Total & 21 & 20 & 4 \\
\hline
\end{tabular}

ALS had nurses and emergency medical technician with ambulance equipped with airway equipment, cardiac life support, cardiac monitors and glucose testing device. BLS had two emergency medical technicians and not fully equipped. 
In terms of response time, neighbour's car and private vehicles were the fastest, taking an average time of $15 \pm 6$ minutes and $20 \pm 9$ minutes, respectively. Motorbikes and taxis took an average time of $20 \pm 7$ minutes and $35 \pm 13$ minutes. Ambulances took an average time of $40 \pm 17$ minutes, while public transport of $45 \pm 21$ minutes, and police car of $60 \pm 25$ minutes, as shown in Figure 4 .

Ambulances from private agencies were the most expensive means of transport to hospital, followed by taxi and motorbikes. NMS had free ambulance services not known by the public due to lack of public awareness creation. The cost of ambulances was dependent on each case. The average cost was 4,467 Kenya shillings, ranging between 2,000 and 20,000 Kenya shillings. The majority $(57 \%)$ of the respondents had called an ambulance or someone had called an ambulance during the emergency. The main reasons for not calling an ambulance were the lack of an ambulance number, the opinion that ambulances took longer to respond, and the presence of alternative means of transport such as taxis. Most $(96 \%)$ of the study respondents indicated that there was a need for more ambulances. The lack of means to transport patients, who needed emergency care, was a common problem for $42 \%$ of community members.

\section{Discussion}

The WHO recommends an ambulance to population ratio of 1:70,000-100,000. Using these ratios, the current 83 ambulances should optimally serve the people of Nairobi County. Ambulance teams at a time should be available to optimally serve the average of 4.7 million people in Nairobi city. The public awareness on prehospital emergency care and availability of ambulances are key component in EMS. From this study, the majority (90\%) of the respondents were aware of the role of ambulances in emergency
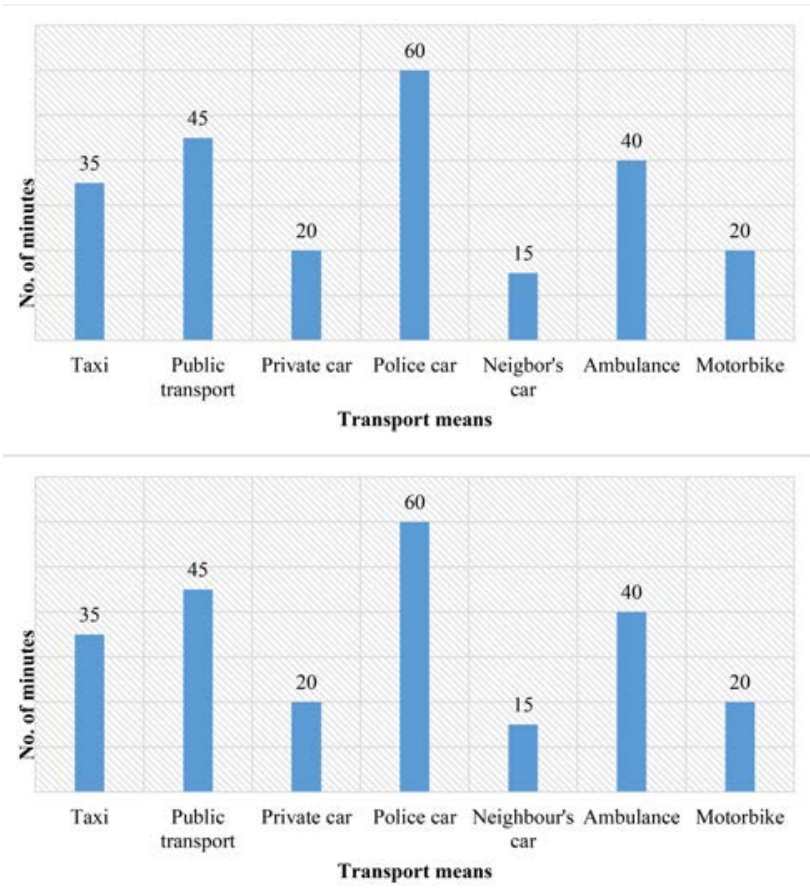

Figure 4. Means of transport and time taken to reach the hospital, expressed as average of minutes. response, but about $70 \%$ of them were not aware of the emergency contact numbers for the ambulance, because they had never been in an emergency before. It was surprising to note that only $21 \%$ of the respondents had called an ambulance, while the remaining respondents had never accessed this service before. Respondents reported that motorcycles and taxi drivers were the most common first responders in the majority of emergency cases. In a previous study conducted in 2003, the predominant means of transportation to hospital were private cars and taxis $(75 \%)^{10}$. Ninety-two per cent of the survivors had no medical interventions instituted before their arrival at the hospital. This implies that, over this period (almost 2 decades), there has not been a significant improvement in the utilization of pre-hospital emergency care ambulances in Nairobi. The average time to medical care in this study ranged from 15 to 60 minutes. Generally, there is an improvement in the response time compared to a study conducted in 2003, where response was slower taking 2.56 hours with only $17.5 \%$ patients reached their areas of definitive care within 60 minutes. ${ }^{10}$ Collaboration of different pre-hospital emergency care service providers can be adopted as an initiative to reduce emergency response time. In South Nigeria, where pre-hospital emergency services were not available, collaboration of Nigeria Red Cross, Police, Army, and Road safety patrol teams led to an average response time of 10-30 minutes and salvaged many victims from road accident scenes. ${ }^{12}$ In our study, the first responders do not have adequate training on first aid and medical response. This observation is mconfirmed in a study by Macharia et al. that showed that $76.5 \%$ of 310 road traffic injury casualties were transported to hospitals by predominantly other road users or general public without or little knowledge on first aid. ${ }^{6}$ In this study, the lay public was often left to decide independently whether and where to transfer their acutely ill or injured patients. This was due to the lack of clarity on the operations of the extant pre-hospital emergency care system. Similarly, a study published by Said and Kahoro in 2001 reported the lack of systematized and uniformly haphazard pre-hospital and initial care among injured traffic road accident victims. ${ }^{12}$

It was noted that only 3 out of 14 dispatch centers had toll free emergency numbers, further alienating persons without adequate airtime on their mobile phones. This reduces the rate of reporting and hence speed of response by the emergency teams as first responders are charged for reporting cases. The capacity building of dispatch center strengthens the link of communication between community, ambulances and facilities. Internationally accepted standards define the minimum standards of a dispatch center as follows: i) a control room with communication radio, ii) operational 24 hours a day, and iii) trained dispatchers that receive calls and redirect the ambulances. Noteworthy is that only 9 of the dispatch centers had the minimum requirements in line with internationally accepted standards. The current fragmented pre-hospital emergency care system replicates that the study highlighted the lack of a coordinated and integrated pre-hospital care system to route injured patients to appropriate care facilities in Kenya. ${ }^{2,9}$ At the time of the study, NMS had an emergency operations center (EOC) available 24 hours with a toll-free number. However, the public was not aware about the EOC nor their contacts, which is likely to reduce chances of utilizing or activating ambulance in case of emergency. As in other LMICs, pre-hospital care system in Kenya is marred with inefficiencies, that result in a risky delay even fatal. ${ }^{2}$ A landscape analysis demonstrated that less than one in three African countries has a pre-hospital EMS in place with limited capacity to respond, evaluate, treat, and safely transport patients. ${ }^{3}$ Surely, collaboration of different pre-hospital emergency 
service providers can help both reduce response time and save lives. ${ }^{13}$

\section{Conclusions}

The successful implementation of EMS forms the base of a functioning healthcare system and eases pressure on every other branch of that system. Some of the challenges faced in pre-hospital emergency care include the delayed communication to dispatchers due to several factors, such as: the low public awareness of ambulance service numbers to call in an emergency; the lack of a single short-code emergency ambulance access number; the lack of a well-connected, reliable central dispatch system; and the limited number of public ambulances and staff. Most patients reached the hospital by private means, e.g., taxis, private cars, trucks, tuk-tuk, motor bike riders etc., which delayed medical care and exposed them to further medical complications. Our study highlights the need for interventions that shorten EMS response time. It is paramount to sensitize and train community as first responders, especially motorists who are always the first to arrive at the scene of an accident, teach them how to build and maintain a kit for first aid services and immediately contact EMS. Specifically, the government needs to be involved in public enlightenment, training paramedics, and provision of free ambulance services to the majority poor citizenry to reduce pre-hospital deaths. In addition, it is necessary to include ambulance insurance as the government rolls out the universal health coverage. Improving public pre-hospital emergency care systems is high-impact and cost-effective, and critical for overall health systems strengthening.

\section{References}

1. Mistovich J, Hafen B, Karren K. Prehospital emergency care. 8th ed. Brady Prentice Hall Health: USA; 2007.

2. Waseem H, Naseer R, Razzak J. Establishing a successful prehospital emergency service in a developing country: experi- ence from Rescue 1122 service in Pakistan. Emerg Med J 2011;28:513-5.

3. Onyachi N, Maniple E, Santini S. Preparedness for mass casualties of road traffic crashes in Uganda: assessing the surge capacity of highway general hospitals. Health Policy Dev 2011;9:17-26.

4. Broccoli M, Calvello E, Skog A. Perceptions of emergency care in Kenyan communities lacking access to formalised emergency medical systems: a qualitative study. BMJ Open 2015;5:e009208.

5. Koome G, Atela M, Thuita F, Egondi T. Health system factors associated with post-trauma mortality at the prehospital care level in Africa: a scoping review. Trauma Surg Acute Care Open 2020;5:e000530.

6. Macharia W, Njeru E, Muli-Musiime F, Nantulya V. Severe road traffic injuries in Kenya, quality of care and access. Afr Health Sci 2009;9:118-124.

7. Nicholson B, McCollough C, Wachira B, Mould-Millman NK. Emergency medical services (EMS) training in Kenya: Findings and recommendations from an educational assessment. Afr J Emerg Med 2017;7:157-9.

8. Sriram V, Gururaj G, Razzak J. Comparative analysis of three emergency medical services organizations in India and Pakistan. Public Health 2016;137:169-7.

9. Stevens KA, Paruk F, Bachani AM, et al. Establishing hospital-based trauma registry systems: lessons from Kenya. Injury 2013;44:S70-S74.

10. Saidi HS. Initial injury care in Nairobi, Kenya: a call for trauma care regionalization. East Afr Med J 2003;80:480-3.

11. Wachira BW. The state of emergency care in the Republic of Kenya. Afr J Emerg Med 2011;1:160-5.

12. Jasper A, Jasper G, Edah I, Edah C. Pre-hospital care of road traffic accident victims in the Niger Delta: a private initiative and experience. Open Access Emerg Med 2019;2019:51-6.

13. Said H, Kahoro P. Experience with road traffic accident victims at the Nairobi hospital. East Afr Med J 2001;78:441-7. 
